\title{
Determination of Radionuclides in Soil Samples Taken From Gura Topp (Jos) Using Sodium lodide Thallium Detector Nai(Ti)
}

\author{
${ }^{* 1}$ M.S. Abdulkarim, ${ }^{2}$ S. Umar, ${ }^{3}$ A. Mohammed and ${ }^{1}$ D. Modelu \\ 1Department of Applied Physics, College of Science and Technology Kaduna Polytechnic, Kaduna, Nigeria \\ 2Department of Physics, Faculty of Science, Ahmadu Bello University Zaria, Nigeria \\ 3Department of Physic, School of Science, Federal College of Education (Tech), Gusau, Zamfara, Nigeria \\ [Corresponding Author: E-mail: sanikareem@yahoo.com; D:08063165555]
}

\begin{abstract}
The activity concentrations of natural radionuclides ${ }^{40} \mathrm{~K},{ }^{226} \mathrm{Ra}$ and ${ }^{232} \mathrm{Th}$ in soil samples taken from the tin mining area in Gura top, Jos were measured by gamma spectrometry using Sodium lodide detector. The average specific activity concentrations of ${ }^{40} \mathrm{~K},{ }^{226} \mathrm{Ra}$ and ${ }^{232} \mathrm{Th}$ determined in the soil sample ranged from $11.26 \pm 3.16 \mathrm{~Bq} / \mathrm{Kg}$ to $543.35 \pm 0.64 \mathrm{Bg} / \mathrm{Kg}$ with mean activity concentration of $161.96 \pm 7.56 \mathrm{~Bq} / \mathrm{Kg}$ for $40 \mathrm{~K}$, that of ${ }^{226} \mathrm{Ra}$ ranged from $7.19 \pm 1.23 \mathrm{~Bq} / \mathrm{Kg}$ to $144.20 \pm 10.18 \mathrm{~Bq} / \mathrm{Kg}$ with the mean activity of $46.47 \pm 5.19 \mathrm{~Bq} / \mathrm{Kg}$ while $232 \mathrm{Th}$ ranged from $76.08 \pm 3.38 \mathrm{~Bq} / \mathrm{Kg}$ to $1267.91 \pm 15.37 \mathrm{~Bq} / \mathrm{Kg}$, with mean activity concentration of $396.17 \pm 7.69 \mathrm{~Bq} / \mathrm{Kg}$. The results indicates that the activity concentration of $40 \mathrm{~K}$ was found to be below the world average while that of ${ }^{232} \mathrm{Th}$ and ${ }^{226} \mathrm{Ra}$ were detected to be above the world average value. This suggests that $t$ the study area has excess thorium and radium activities which pose significant health hazard and is considered radio-logically unsafe for human to cultivate on the land.
\end{abstract}

Keywords: Activity concentration, Gamma spectrometry, Natural radionuclides and Sodium, lodide detector.

\section{INTRODUCTION}

Human beings are exposed to radiation arising from sources including cosmic rays, natural radionuclides in water, air, soil and plants; and artificial radioactivity from fallout in nuclear testing and medical applications. The gamma radiation from natural radionuclides and cosmic rays constitute the external exposure while those derived from inhalation and ingestion through foods and drinking water constitutes internal exposure to humans (Augustine et al., 2014). In addition, ICRP (1999) publication shows that man is continuously exposed to ionizing radiation from naturally occurring radioactive materials and attributed the origin of these materials to earth's crust. IAEA (1996) estimated that $80 \%$ of doses contributions in the environment are derived from the natural radionuclides while the remaining $20 \%$ is from cosmic ray and nuclear processes. Natural radioactivity is widely spread in the earth's environment and depends primarily on the geological and geographical conditions, and appears at different levels in the soils of each region in the world (UNSCEAR, 2000).

Soil pollution comprises the pollution of soils with materials. Some of these pollutants are radionuclides and can also be sourced from naturally occurring radioactive materials of the earth's crust, which emits alpha, beta and gamma radiations.

Tin mining and processing constitute a source of pollution to the environment (Adiuku-Brown and Ogezi, 1991). The mining of tin facilitates the release of radioactive minerals from the host rocks into the environment (Jiya and Musa, 2012). Study by Adiuku-Brown \& Ogezi et al. (1991) has indicated rather high level of radioactive waste resulting from mining in plateau in Jos. Radionuclides has biological effects on the organs and tissues in the body. Therefore, there is need to determine the specific activities of the radionuclides present in soil.

Soil pollutants from residential, industrial (mining sites) and hospital waste, as well as from fertilizers on farmlands and the naturally occurring radioactive materials (NORM) in a particular area affect the quality of the soil in that area. Some of these pollutants are radioactive and their deposition into the human body can be hazardous to health. In Jos town, the river that runs is greatly used for irrigation. The settlements along the Jos town (Gura topp) are in three categories: the predominantly farming activity region, the residential/commercial region and the industrial 
region. It may be possible that the soil in Guratopp is contaminated with high concentration of radionuclides resulting from activities in the three regions. It is therefore necessary to determine the radionuclides present in soil from the three regions of the Guratopp and to determine the region whose activities possess radiological hazards to the inhabitants of Jos via the soil samples.

Radionuclides determination as stipulated for the acceptable world average value of $232 \mathrm{Th}, 238 \mathrm{U}$ and $40 \mathrm{~K}$ is $35 \mathrm{~Bq} / \mathrm{kg}, 35 \mathrm{~Bq} / \mathrm{kg}$ and $420 \mathrm{~Bq} / \mathrm{kg}$ respectively (UNSCEAR, 2000). This survey is important in the sense that it is concerned with the health of the populace. It is equally economical because it provides data necessary for complete purification of soil (plants) from Guratopp and if the soil in the region is safe, some health problems will be eliminated and government will save a lot of money for other developmental effects. Since this research is a regional one, other bodies or organisations wishing to carryout survey of radionuclides in soil in a broader scope will use this work as a reference point for the detailed survey. Also, the data from this research will form the basis for the radionuclide specific test where the test is necessary, hence the research will continue immensely to literature.

In summary, this article evaluates the presence of radionuclides in soil samples and will also the level of concentration of radionuclides in the soil samples.

\section{MATERIAL AND METHOD \\ Study area}

The study area is located at GuraTopp, Jos and its environment where artisanal gold mining activities are taking place in Jos South Local Government Area of Plateau State.

\section{Sample Collection}

Soil samples were collected from various locations within the mines and the surrounding community in Gura topp, Jos. To ensure that representative samples were taken, an initial survey was carried out in the area to determine the sampling points. The selection of sampling locations was based on the accessibility to the public and proximity to the mine. In addition, the geological map of the area was used to identify the locations where samples were taken. Based on these criteria, twelve (12) locations were identified and soil samples were collected. The sampling locations were marked using a geographical positioning system (GPS). Random sampling was adopted in collecting the soil samples from depth of $5-10 \mathrm{~cm}$ using a coring tool within defined boundaries of the area of concern into plastic bags that were labelled to prevent mix up. At each sampling location, samples of soil were taken from different sections of the area into labelled plastic bags. One-kilogram $(1 \mathrm{Kg})$ of each of the samples were collected and transported to the Centre for Energy Research and Training Ahmadu Bello University, Zaria for preparation and analysis with a Sodium lodide Thallium $\mathrm{Nal}(\mathrm{Ti})$ ) detector. The locations from which the samples were collected are listed below.

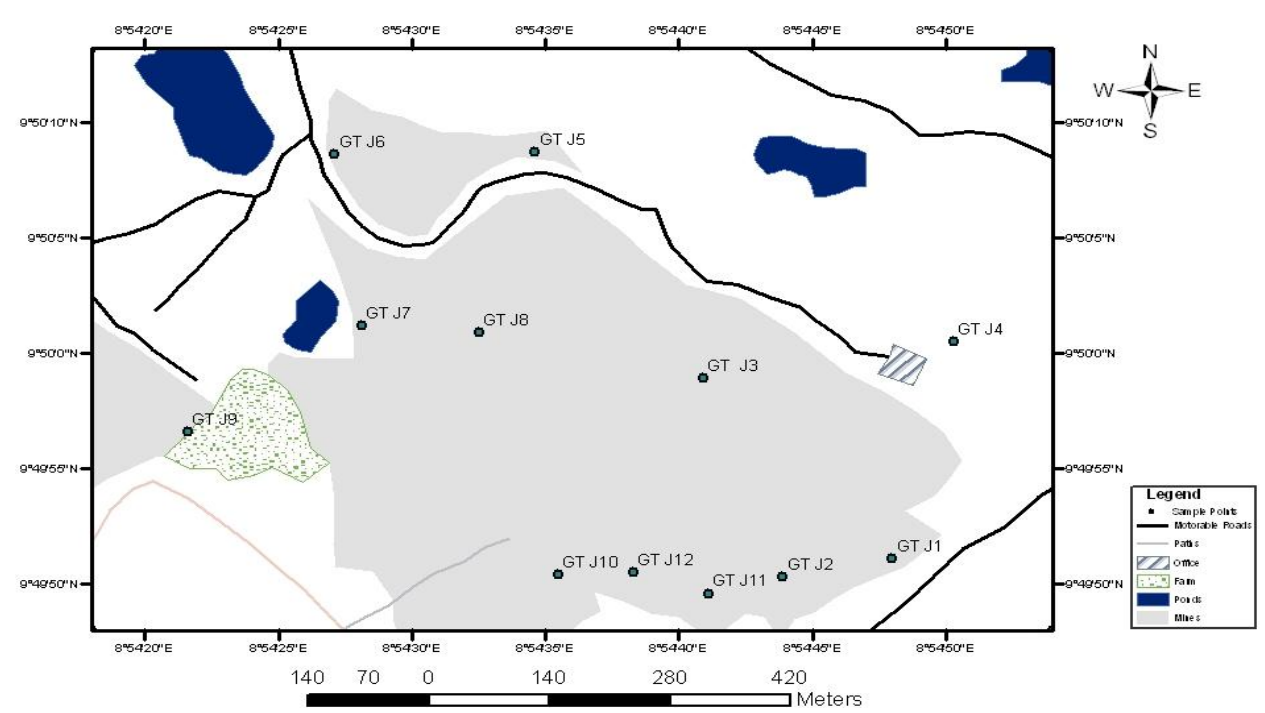

Figure 1: Map of sites, Gura-topp area Jos. 
Table 1: Soil Sample Taken From Gura Topp (GRT) Jos and there Coordinates

\begin{tabular}{llllc} 
S/N & Sample ID & Northings & Easting's & Elevation (metres) \\
\hline 1 & GRT S1 & $90^{\circ} 49^{\prime} 51.1^{\prime \prime}$ & $80^{\circ} 54^{\prime} 48.0^{\prime \prime}$ & $1,306 \mathrm{~m}$ \\
2 & GRT S2 & $90^{\circ} 49^{\prime} 50.3^{\prime \prime}$ & $80^{\circ} 54^{\prime} 42.9^{\prime \prime}$ & $1,294 \mathrm{~m}$ \\
3 & GRT S3 & $90^{\circ} 49^{\prime} 58.9^{\prime \prime}$ & $80^{\circ} 54^{\prime} 40.9^{\prime \prime}$ & $1,295 \mathrm{~m}$ \\
4 & GRT S4 & $90^{\circ} 50^{\prime} 0.49^{\prime \prime}$ & $80^{\circ} 54^{\prime} 50.3^{\prime \prime}$ & $1,317 \mathrm{~m}$ \\
5 & GRT S5 & $90^{\circ} 50^{\prime} 8.7^{\prime \prime}$ & $80^{\circ} 54^{\prime} 34.6^{\prime \prime}$ & $1,295 \mathrm{~m}$ \\
6 & GRT S6 & $90^{\circ} 50^{\prime} 8.6^{\prime \prime}$ & $80^{\circ} 54^{\prime} 27.1^{\prime \prime}$ & $1,291 \mathrm{~m}$ \\
7 & GRT S7 & $90^{\circ} 50^{\prime} 1.2^{\prime \prime}$ & $80^{\circ} 54^{\prime} 28.1^{\prime \prime}$ & $1,296 \mathrm{~m}$ \\
8 & GRT S8 & $90^{\circ} 50^{\prime} 0.9^{\prime \prime}$ & $80^{\circ} 54^{\prime} 32.52^{\prime \prime}$ & $1,297 \mathrm{~m}$ \\
9 & GRT S9 & $90^{\circ} 49^{\prime} 56.6^{\prime \prime}$ & $80^{\circ} 54^{\prime} 21.6^{\prime \prime}$ & $1,284 \mathrm{~m}$ \\
10 & GRT S10 & $90^{\circ} 49^{\prime} 50.4^{\prime \prime}$ & $80^{\circ} 54^{\prime} 35.5^{\prime \prime}$ & $1,232 \mathrm{~m}$ \\
11 & GRT S11 & $90^{\circ} 49^{\prime} 49.6^{\prime \prime}$ & $80^{\circ} 54^{\prime} 41.1^{\prime \prime}$ & $1,299 \mathrm{~m}$ \\
12 & GRT S12 & $90^{\circ} 49^{\prime} 50.5^{\prime \prime}$ & $80^{\circ} 54^{\prime} 38.3^{\prime \prime}$ & $1,296 \mathrm{~m}$ \\
\hline
\end{tabular}

GRT=GURA TOPP

$S=$ SAMPLE

12 soil sample taken from gura topp (GRT) Jos and there coordinates: SAMPLE ID, northings, easting's and, elevation (metres) of each sample.

\section{Sample preparation}

Samples collected was dried for $24 \mathrm{~h}$ under ambient temperature and crushed to fine powder with the use of a pulverizer. This was followed by packaging the samples into radon-impermeable cylindrical plastic containers which were selected based on the space allocation of the detector vessel which measures $7.6 \mathrm{~cm}$ by $7.6 \mathrm{~cm}$ in dimension. To prevent radon-222 from escaping, the packaging in each case was triple-sealed. The sealing process includes smearing of inner rim of each container lid with Vaseline jelly, filling the lid assembly gap with candle wax to block the gaps between lid and container, and tight-sealing lidcontainer with masking adhesive tape. The prepared samples were then stored for a period of about 30 days to allow for radon and its short-lived progenies to reach secular radioactive equilibrium prior to gamma spectroscopy measurement.

\section{Energy Calibration of Sodium lodide Thallium Gamma Spectroscopy System}

Before the counting commenced, the two gamma standard sources (Cs-137 and Co-60) were placed into $6 \mathrm{~cm}$ lead shield of $\mathrm{Nal}(\mathrm{TI})$ detector chamber. This arrangement is aimed at minimizing the effects of background and scattered radiation. These were done with the amplifier gain that gives $72 \%$ energy resolution for the $66.16 \mathrm{KeV}$ of $\mathrm{Cs}-137$ and counted for 30 minutes.

\section{The Measurement System}

This consists of a $7.62 \mathrm{~cm} \times 7.62 \mathrm{~cm} \mathrm{Nal(TI)}$ detector crystal, optically coupled to a photomultiplier tube. The assembly has a preamplifier incorporated into it and a 1 kilovolt external source. The data acquisition software used was the Maestro by Canberra Nuclear Products. Each sample was measured for a period of 29000 seconds. The peak area for each energy in the spectrum was used to compute the activity concentrations in each sample using the following equation:

$C=\frac{C n}{C_{f k}}$

Where, $\quad \mathrm{C}=$ activity concentration of the radionuclides in the sample given in $\frac{\mathrm{Bq}}{\mathrm{Kg}}$

$\mathrm{Cn}$

$=$ count rate or count per second (cps)

$=\frac{\text { Net Count }}{\text { Live Time }}$

$C_{f k}$

= Calibration factor of detecting system All the obtained raw data were then converted to conventional units using calibration factors to determine the activity concentrations of $K-$ 40, Th - 232 and $R a-226$. 
RESULTS AND DISCUSSION

Table 2. Activity concentration of ${ }^{40 \mathrm{~K}},{ }^{226} \mathrm{Ra}$, and ${ }^{232} \mathrm{Th}$ in the soil samples taken from gura topp (GRT) Jos.

\begin{tabular}{lllll} 
S/No & Sample ID & $40 \mathrm{~K}(\mathrm{~Bq} / \mathrm{Kq})$ & $226 \mathrm{Ra}(\mathrm{Bq} / \mathrm{Kg})$ & 232Th $(\mathrm{Bq} / \mathrm{Kg})$ \\
\hline 1 & GRT S1 & $81.03 \pm 21.88$ & $86.18 \pm 9.23$ & $564.58 \pm 11.67$ \\
2 & GRT S2 & $11.26 \pm 3.160$ & $60.93 \pm 3.19$ & $141.94 \pm 4.60$ \\
3 & GRT S3 & $51.16 \pm 18.6$ & $53.26 \pm 1.39$ & $1267.91 \pm 15.37$ \\
4 & GRT S4 & $107.04 \pm 4.82$ & $8.99 \pm 1.75$ & $310.46 \pm 7.31$ \\
5 & GRT S5 & $89.07 \pm 2.09$ & $7.19 \pm 1.23$ & $210.9 \pm 4.52$ \\
6 & GRT S6 & $37 \pm 7.07$ & $45.23 \pm 3.79$ & $314.04 \pm 6.52$ \\
7 & GRT S7 & $151.39 \pm 6.27$ & $84.34 \pm 5.03$ & $146.93 \pm 4.24$ \\
8 & GRT S8 & $92.29 \pm 4.55$ & $17.18 \pm 3.75$ & $76.08 \pm 3.38$ \\
9 & GRT S9 & $510.75 \pm 4.98$ & $15.62 \pm 6.67$ & $332.08 \pm 6.88$ \\
10 & GRT S10 & $226.14 \pm 13.24$ & $22.25 \pm 7.59$ & $267.95 \pm 7.39$ \\
11 & GRT S11 & $543.35 \pm 0.64$ & $144.2 \pm 10.18$ & $579.32 \pm 10.02$ \\
12 & GRT S12 & $43.06 \pm 3.37$ & $12.22 \pm 8.43$ & $541.89 \pm 10.34$ \\
\hline
\end{tabular}

\section{GRT=GURA TOPP}

$S=$ SAMPLE

Table 2 shows the activity concentration of ${ }^{40} \mathrm{k},{ }^{226} \mathrm{Ra}$, and ${ }^{232} \mathrm{Th}$ in 12 soil samples taken from the tin mining area in Gura topp Jos.

Table 3: Statistical analysis of the activity concentration of ${ }^{40} \mathrm{~K}(\mathrm{~Bq} / \mathrm{Kq}),{ }^{226} \mathrm{Ra}(\mathrm{Bq} / \mathrm{Kq})$, and ${ }^{232} \mathrm{Th}(\mathrm{Bq} / \mathrm{Kq})$ in the soil samples taken from Gura Topp (GRT) Jos

\begin{tabular}{llll}
\hline & $40 \mathrm{~K}(\mathrm{~Bq} / \mathrm{Kq})$ & ${ }^{226} \mathrm{Ra}(\mathrm{Bq} / \mathrm{Kq})$, & $232 \mathrm{Th}(\mathrm{Bq} / \mathrm{Kq})$ \\
\hline Mean & $161.96 \pm 7.56$ & $46.47 \pm 5.19$ & $396.17 \pm 7.69$ \\
Minimum & $11.26 \pm 3.160$ & $7.19 \pm 1.23$ & $76.08 \pm 3.38$ \\
Maximum & $543.35 \pm 0.64$ & $144.2 \pm 10.18$ & $1267.91 \pm 15.37$ \\
\hline
\end{tabular}

Table 3 is the statistical analysis of the activity concentration of ${ }^{40} \mathrm{~K},{ }^{226} \mathrm{Ra}$, and ${ }^{232} \mathrm{Th}$ in 12 soil samples taken from the tin mining area in Gura topp Jos

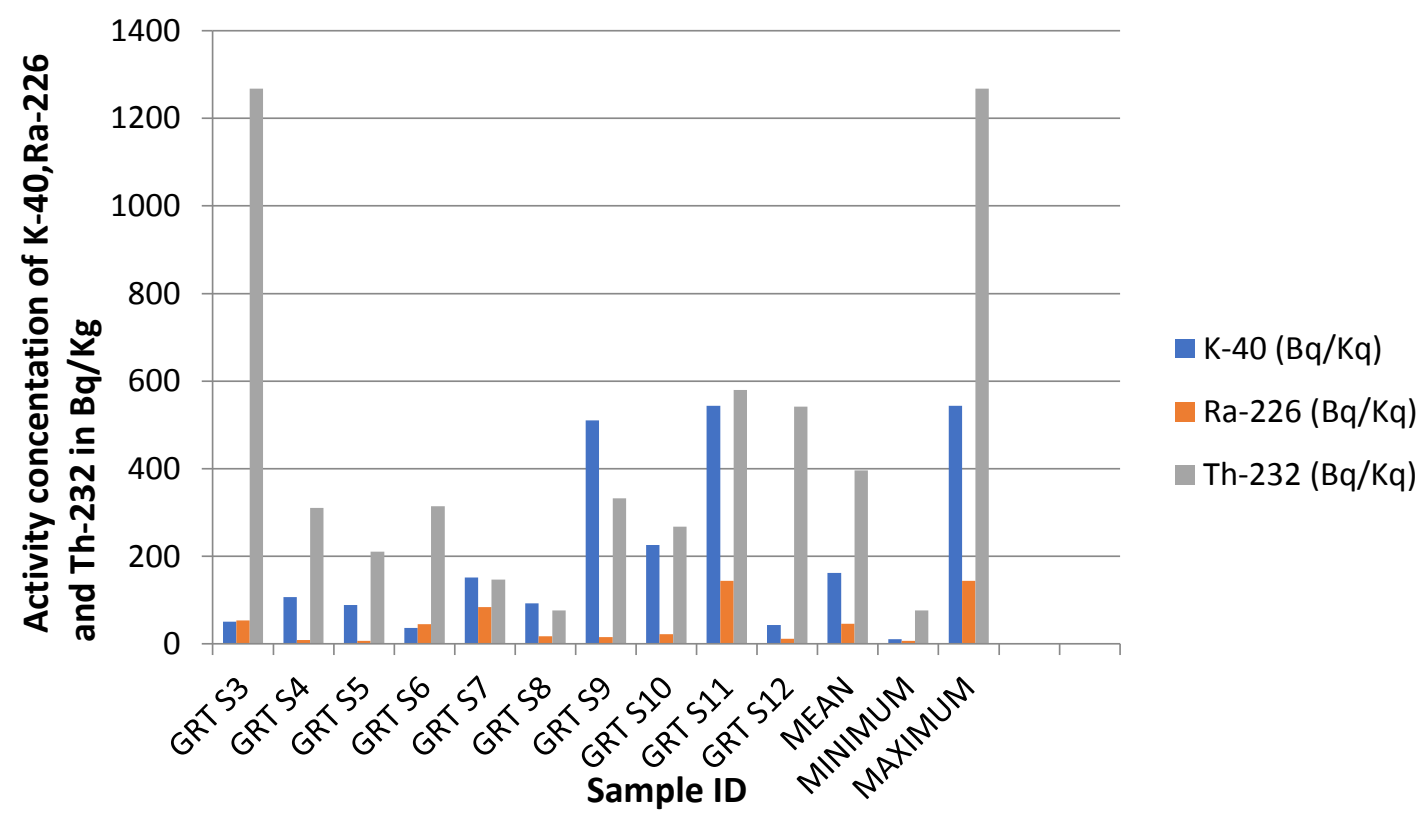

Figure 2: Graph of Activity Concentrations of ${ }^{40} \mathrm{~K},{ }^{226} \mathrm{Ra}$, and ${ }^{232} \mathrm{Th}(\mathrm{Bq} / \mathrm{kg})$ against Sample ID 


\section{DISCUSSION}

From Table 2, the highest activity concentration of the three natural radionuclides ${ }^{40} \mathrm{k},{ }^{226} \mathrm{Ra}$, and 232Th were found in the soil samples collected from GRTS11 (543.35 $\pm 0.64 \mathrm{~Bq} / \mathrm{Kg})$, GRTS11(144.20 \pm $10.18 \mathrm{~Bq} / \mathrm{Kg})$ and GRTS3 $(1267.91 \pm 15.37 \mathrm{~Bq} / \mathrm{Kg})$ and the lowest activity concentration were measured from soil samples collected from GRTS2 $(11.26 \pm 3.16 \mathrm{~Bq} / \mathrm{Kg})$, GRTS5 $(7.19 \pm 1.23 \mathrm{~Bq} / \mathrm{Kg})$ and GRTS8 $(76.08 \pm 3.38 \mathrm{Bg} / \mathrm{Kg})$ respectively (Abdulkarim and umar 2013). Previous studies have shown that soils and rocks of granite composition contain significant amounts of terrestrial radionuclides. When brought to the surface through mining activities, these radionuclides in mine tailings may result in enhanced background radiation levels, exposing the miners and the people living around the mines with higher doses of gamma radiation. There is increasing evidence that improper use or disposal of such naturally-occurring radioactive materials can result in significant contamination of the environment and elevated radiation exposure. This can adversely affect the health of those occupationally exposed, as well as the general public.(Abdulkarim and Sadiq 2013).

\section{CONCLUSION}

Gamma-ray spectrometry definitely appeared to be a useful and sensitive method for obtained information on radionuclide in the environment. The result in this work shows that the activity concentration of ${ }^{40} \mathrm{~K}(11.26 \pm 3.160$ to $543.35 \pm 0.64$ ) and the mean activity concentration of $161.96 \pm 7.56 \mathrm{~Bq} / \mathrm{Kg}$ for ${ }^{40 \mathrm{~K}}$ is below the world average while the activity concentration of $232 \mathrm{Th}$ (76.08 \pm 3.38 to $1267.91 \pm 15.37)$ with mean activity concentration of $396.17 \pm 7.69 \mathrm{~Bq} / \mathrm{Kg}$. which is far above the world average value and ${ }^{226} \mathrm{Ra}$ from (7.19 \pm 1.23 to $144.2 \pm 10.18)$ with mean activity concentration of $46.47 \pm 5.19 \mathrm{~Bq} / \mathrm{Kg}$ is above the world average. Results from the twelve (12) samples analysed also indicate that the mean activity concentration due to thorium in the soil sample ranked highest against the lowest value obtained from radium as shown Figure 2. This therefore, suggested that the level of exposure to radiation in the study area has excess thorium and radium, the most common radiation induced health effects are incidence of cancer and genetic effects.
Lung cancer induction is the most common effect due to inhalation of radiation exposure. Therefore, soils from Guratopp (Jos) along the mining site may pose radiological hazards to the inhabitants of Plateau and therefore the need to be further investigated by other researchers.

\section{REFERENCES}

Abdulkarim, M.S. Sadiq, U. and Zakari, I.Y. ( 2013). Determination of Radionuclides in Building Blocks Made in Kaduna Metropolis. International Journal of Science and Technology, 2(12): 866-868.

Abdulkarim, M.S. and Umar, S. (2013). An Investigation of Natural Radioactivity around Gold Mining Sites in B irnin Gwari North Western Nigeria. Research Journal of Physica I Sciences, 1(7): 20-23.

Adiuku-Brown, M. E. and Ogezi, A. E. (1991). Heavy Metal Pollution from Mining practices: A case study of ZurakJournal of Mining and Geology, 8(1), 71-77.

Augustine, K. A, Adekunle, K.B. and Adeniyi, C.A. (2014).Determination of naturalradioactivity and hazard in soil samples in and around gold mining area in Itagunmodi, SouthWestern, Nigeria, Journal of Radiation Research and Applied Sciences, 7(2):249255.

Commission on Radiological Protection (1999), Protection of the public insituations of prolonged Radiation Exposure, Publication 82, Elsevier Science, 1-103.

International Atomic Energy AgencylAEA (1996).

International Commission on Radiological protection ICRP (1999).

Jiya S.N. and Musa, H.D (2012). Impacts of Derived Tin MiningActivities on Landuse/Landcover in Bukuru, Plateau State, Nigeria, Journal of Sustainable Development, 5(5): 90-100.

UNSCEAR: (2000) Report to general assembly. With scientific annexes."Sources and Effectsof Ionizing Radiation", United Nations sales Publications No. E.00.IX.3 Volume I: Sources and No. E.00.IX.4 (Volume II: Effects). United Nations, New York, 1220 pp.

World Health Organisation (WHO). (2009) 'Handbook on indoor radon, a publicHealthPerspective', Department of Public Health and Environment,Geneva, ISBN 978-92-41547673. 